\section{Independence and oral health: implications of the Scottish referendum}

\author{
C. M Jones ${ }^{1}$
}

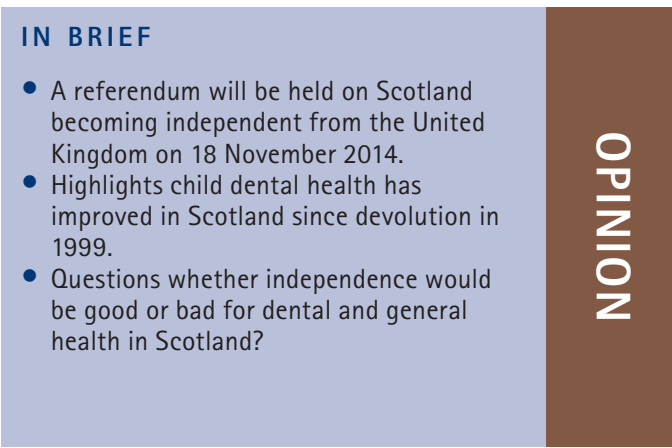

On 18 September 2014, a referendum will be held on Scotland becoming a nation independent from the rest of the United
Kingdom. Since devolution in 1999 child dental health in Scotland has improved significantly, although the National Health
Service in Scotland has always been governed through a separate legislative framework from that in England and Wales.
Scotland was also first to introduce a ban on smoking in public places and is pursuing minimum alcohol pricing to directly
improve public health. This article explores if a vote for an independent Scotland would influence either dental and/or
general health.

On 18 of September 2014, all people over 16 years of age on the electoral register in Scotland are entitled to vote in a referendum on Scotland becoming a nation independent from the remainder of the United Kingdom. ${ }^{1}$

One difference from normal voting arrangements is the minimum age for participants in the referendum. People who will be 16 years old by 18 September 2014, and are otherwise eligible, can register to vote. Coming of age or the 'age of majority' is the legal threshold of adulthood. In Scotland the age of majority is 16 years, already a difference to the remainder of the UK and most European countries, where it is typically 18 years. It is the moment when a child stops being a minor and assumes control over their actions and decisions. ${ }^{2}$

Speculation on what the implications of an independent Scotland might be for public health policies and many other issues continues $^{3}$ and this article explores what the possible implications might be for dentistry.

The forthcoming referendum cannot be categorised as 'a little local matter.' If the result is a simple majority in favour, the Scottish Government expects fast track admission to Europe under article 48 of the Treaty of Europe, which would require unanimous support of all European Union (EU) countries. ${ }^{4}$ But a number of EU countries have stated that an independent Scotland will not gain automatic entry as there is a waiting list!

Consultant in Dental Public Health

Correspondence to: Colwyn M. Jones

Email:colwyn.jones@nhs.net

Accepted 28 May 2014

DOI: 10.1038/sj.bdj.2014.592

${ }^{\circledR}$ British Dental Journal 2014; 217: 65-66
They reflect concern that other areas might start to actively seek independence (Catalans) Basques in Spain, Walloons in Belgium, Wales in the UK, The Northern League in Italy, Bavaria in Germany, etc) Under article 49 of the Treaty of Europe, Scotland would then go on the waiting list as a new applicant country. Within Scotland EU membership is generally viewed as positive, in comparison to some other parts of the UK, and especially when viewed after the recent elections to the European Parliament.

Devolution was a constitutional settlement introduced in the UK in 1999, designed to decentralise government through devolving responsibilities for some legislation to the new Scottish Parliament, the Welsh assembly and the Northern Irish Assembly. Devolution has been welcomed in Scotland, and as health was a devolved responsibility, reviewing what has changed in the dental public health field since then might help to inform discussion before the referendum and what the future might hold for oral health and general health in an independent Scotland.

Child dental health in Scotland has seen steady and welcome improvement since devolution in 1999. The percentage of dentally healthy Scottish primary 1 children (5-year-olds) free from obvious deciduous tooth decay experience has seen a steady, stunning improvement, rising from $45.1 \%$ in 2000 (a year after devolution) to $67 \%$ by 2012 . For primary 7 children (11-yearolds) this has improved from 52.9\% in the permanent dentition in 2005 to $72.8 \%$ in 2013, all free of tooth decay experience., Credit for this dental health improvement is typically given to a national populationbased initiative called Childsmile (http:// www.child-smile.org.uk/). One of the first systematic reviews in dentistry concluded that 'oral health promotion which brings about the use of fluoride is effective for reducing caries.' Childsmile complies with this conclusion and was started in 2005, introduced by the then coalition government of the Scottish Labour party and the Liberal Democrats; incidentally, both campaigning against independence in the 2014 referendum. It was rumoured that the substantial funding made available for Childsmile $^{8,9}$ arose because when in coalition, the Liberal Democrats refused to support legislation on a ban on smoking in public places (Smoking, Health and Social Care [Scotland] Act, 2005) if a clause allowing permissive water fluoridation in Scotland was included. The Westminster (UK) government in Section 58 of the Water Act (Fluoridation of Water supplies) 2003, which applies to England and Wales did include the legislation. Political memoires from that time have yet to confirm or deny this rumour, if they ever will.

In preparation for the referendum, The Scottish Government published a 649 page white paper on Tuesday 26 November 2013 making the case for independence. ${ }^{1}$ I admit that I haven't read it all, and despite the undoubted success of Childsmile, child dental health did not feature in the white paper. A word search using 'dental and dentist' reveals two sections on page 440: '...for hospital-based dentists... the Scottish Government will work with the BMA, and seek to cooperate with the Westminster Government where appropriate, to negotiate pay, terms and conditions' and

The funding and terms and conditions for General Dental Services.......are already devolved and fully negotiated in Scotland. 
These arrangements will also not change. ${ }^{1}$ So radical change to the organisation of NHS dental services, and the NHS more widely, is not seen as a strong driver for Scottish independence.

Devolution started in Scotland and Wales in 1999 and in addition to Childsmile, changes to tobacco and alcohol sales and availability in Scotland shows that there has been good progress in public health policy. As the first part of the UK to implement legislation for smoke-free public places, Scotland continues attempts to reduce the supply of tobacco and alcohol products (Tobacco and Primary Medical Services [Scotland] Act 2010). It has done this through the introduction of a register of all retailers selling tobacco products and a public health supplement (or levy) on larger retailers that sell both tobacco and alcohol (although this may now be repealed).

Scotland has been stereotyped as 'the sick man of Europe' although many other nations have laid claim to the title since the original description of the Ottoman Empire in the 1900 s. $^{10}$ Recent public health legislation on banning smoking in public places and reducing alcohol consumption (including minimum unit pricing) are real achievements of devolution as is the commitment of successive Scottish governments of all complexions to address health inequalities. Again a previous coalition government of Labour and the Liberal Democrats introduced the smoking ban in public places (Smoking, Health and Social Care [Scotland] Act 2005), and the Scottish Nationalist government has vigorously continued their good works. The white paper states independence would allow an independent Scottish Government 'to use the full range of levers to promote good health. ${ }^{1}$ Public health has not, so far, enlivened debate on the forthcoming referendum vote (pensions and currency are currently hot topics!). The target of a 'smoke-free' Scotland by 2034 is a serious public health measure and, in addition to general health benefits, may plausibly produce oral health benefits through reduced periodontal disease and oral cancers; plus less halitosis, less extrinsic staining of teeth and restorations.

Other 'levers' to promote good oral health might be, as mentioned earlier, water fluoridation, reclassification of fluoride toothpaste to a medicine from a cosmetic to avoid VAT to increase sales (if economic theory is correct), or legislation to levy a tax on added sugar in processed foods and drinks. Mandatory salad buffets might also be introduced in restaurants; if you are forced to buy a salad every time you dine out, even in Scotland, you'll probably eat it!

Interestingly legislation that might improve child dental health such as permissive water fluoridation in Scotland is currently in the 1985 Water Fluoridation Act, now consolidated into the 1990 Water Act and is still extant in Scotland. The Water Act (Fluoridation of Water supplies) 2003, in England and Wales was required as private water companies 'had an overriding responsibility to their shareholders, and under the current law, no other consideration (including a public interest such as health).' ${ }^{11}$ Whereas in Scotland water is still a public utility, a further example of the differences devolution has brought, if one were required.

The Scottish government's introduction of plain cigarette packaging and pursuit of minimum alcohol pricing contrasts with the UK government's dithering, although it appears plain packaging will finally be considered by Westminster. ${ }^{12,13}$

Previous progress and ambitious targets suggests that the Holyrood parliament is more comfortable than Westminster developing population-based interventions for public health. So an independent Scotland, with greater powers, could give public health further opportunities for effective general and oral health improvement. It has been stated that; 'Health professions and advocacy groups may have a stronger influence in Edinburgh than in Westminster, reflecting smaller policy communities and a more accessible policymaking system. The exposure of policy makers to policies proposed by health researchers and advocates may therefore have been greater than in Westminster, whereas exposure to other lobbyists may have been lower, given the small number of think tanks, consultancy groups, and commercial headquarters in Scotland. ${ }^{3}$

Would public health remain foremost in an independent Scotland? Health, as a devolved responsibility, is one of the most high profile policy areas for the Scottish government, raising its importance on the policy agenda. If Scotland became an independent nation the government's remit would expand to include fiscal policy (tax and welfare), foreign affairs and defence, almost inevitably reducing its focus on public health. Perhaps also the access and (planned) consensual Scottish parliamentary system, that by comparison to Westminster seems to have favoured public health to date, could work against health if commercial interests increase investment in political activities (lobbying) north of the border. It is plausible that such changes could allow the whisky/soft drinks industry to influence alcohol/sugar tax policies 'in the national interest' by expanding exports of both of Scotland's national drinks! $!^{14,15}$

The white paper, and associated debate, hasn't shown that the 'greater scope and clearer powers' promised by independence would lead to further strengthening of public health controls on diet, alcohol and tobacco regulation. There is an implication that direct control of taxation and advertising regulation would give 'a coherent and concerted approach to... obesity and poor diet. ${ }^{1}$ However, plans to reduce corporation tax below UK levels to create a business friendly Scotland ${ }^{1}$ suggests the strategic political will to improve public health in the face of lobbying from the food and drink industries may be compromised.

While in reality I accept that dental issues are unlikely to be a reason anyone decides how to vote in the September referendum, devolution has provided dental public health and the wider public health workforce with the opportunity to improve child dental health. Could we assume such continued progress within an independent Scotland? Disclaimer: the views presented in this article are solely those of the author.

1. Scottish Government. Scotland's future: your guide to an independent Scotland. Edinburgh: Scottish Government, 2013. Online guide available at http:// www.scotland.gov.uk/Resource/0043/00439021.pdf (accessed June 2014).

2. Jones C M. The European Association of Dental Public Health: coming of age. Community Dent Health 2011; 28: 122.

3. Smith K E, Collin J. Scotland and the public health politics of independence. BMJ 2013; 347: f7595.

4. The Scotsman. No 'fast track' into Europe for Scotland says minister. Edinburgh, The Scotsman, 21 January 2014.

5. National Dental Inspection Programme 2012. ISD Scotland, 2012. Online report available at http:// www.isdscotland.org/Health-Topics/Dental-Care/ Publications/2012-11-27/2012-11-27-DentaINDIPReport.pdf?41798037291 (accessed June 2014).

6. National Dental Inspection Programme 2013. ISD Scotland, 2013. Online report available at http://www.scottishdental.org/index. aspx?0=2153\&trecord=429 (accessed June 2014).

7. Kay E, Locker D. A systematic review of the effectiveness of health promotion aimed at improving oral health. Community Dent Health 1998; 15: 132-144.

8. Audit Scotland. Health inequalities in Scotland Edinburgh: Audit Scotland, 2012. Online report available at http://www.audit-scotland.gov.uk/docs/ health/2012/nr_121213_health_inequalities.pdf (accessed June 2014).

9. Scottish Parliament. S4W-16118: parliamentary questions. Edinburgh: Scottish Parliament, 2013. Online questions available at http://www. scottish.parliament.uk/parliamentarybusiness/ BusinessBulletin/65506.aspx (accessed June 2014).

10. McCartney G, Walsh D, Whyte B, Collins C. Has Scotland always been the 'sick man' of Europe? An observational study from 1855 to 2006. Eur J Public Health 2012; 22: 756-760.

11. Lowry $R$, Evans $D$ J. The privatised water industry and public health: back to square one. Br Dent $J$ 1999; 186: 597-598.

12. Scottish Government. Creating a tobacco free generation: a tobacco control strategy for Scotland. Edinburgh: Scottish Government, 2013.

13. Financial Times. UK government to push ahead on plain-packaged cigarettes. London: Financial Times, 3 April 2014.

14. Holden C, Hawkins B. 'Whisky gloss': the alcohol industry, devolution and policy communities in Scotland. Public Policy Admin 2013; 28: 253-273.

15. The Guardian. Scotland's other national drink. London: The Guardian, 30 May 2007. 